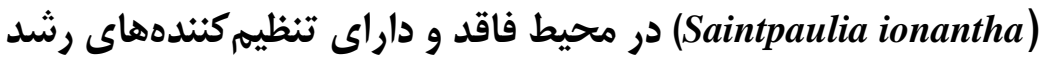

\begin{tabular}{|c|}
\hline 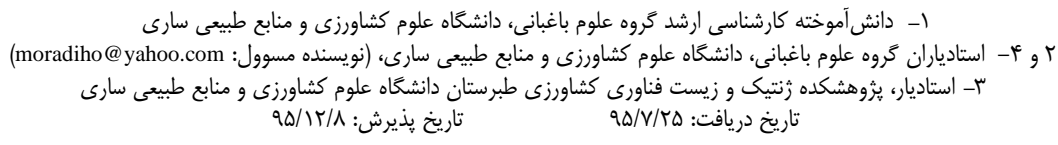 \\
\hline
\end{tabular}

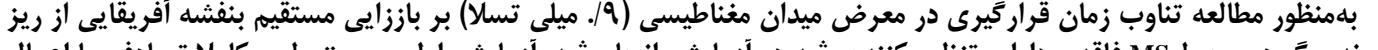

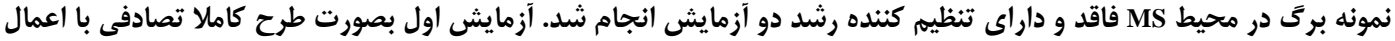

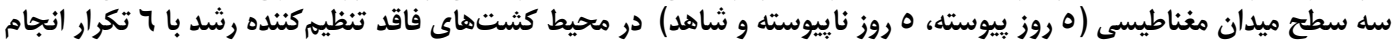

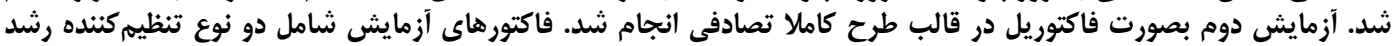

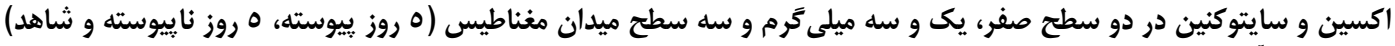

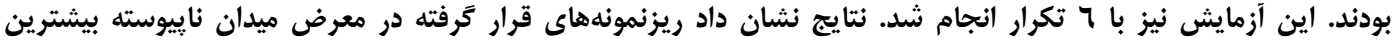
معنى

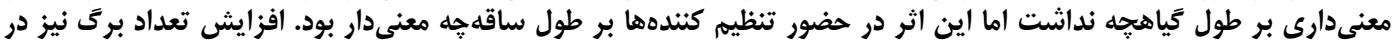

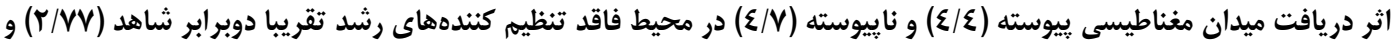

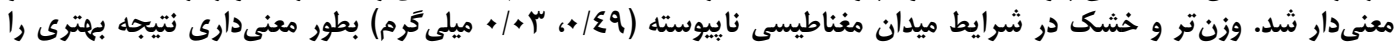

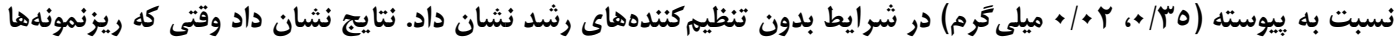

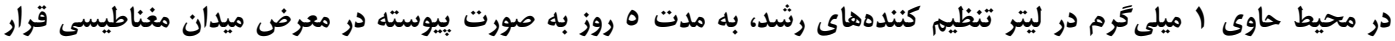

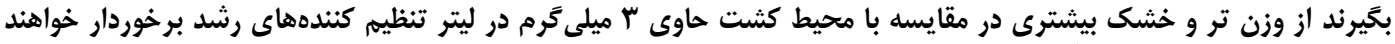

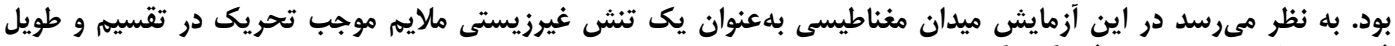
شدن سلولها و در نتيجه رشد كياه ترديد.

وازههاى كليدى: ريزنمونه، تنش، وزن تر و خشك، بنفشه آفريقايى

و الكترومغناطيسى را افزايش داده است (1). بهطور كلى بادي،

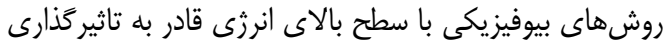

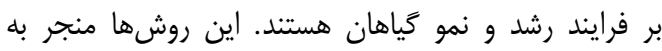

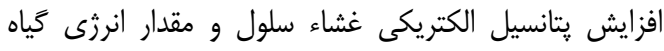

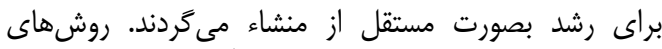

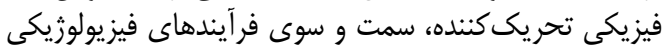

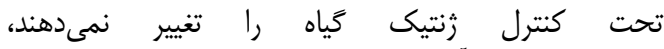

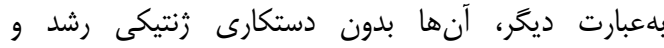

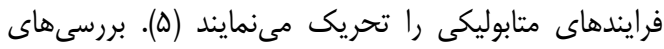

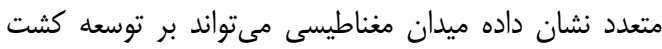

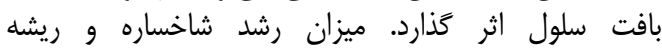

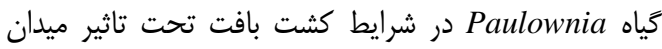

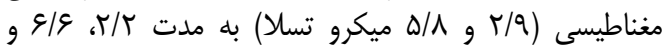

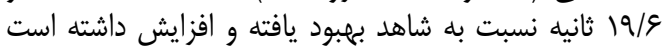
(Y.F.IV)

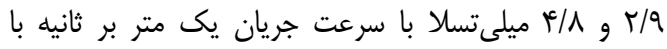

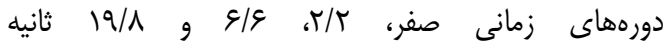

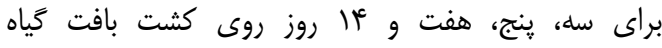
نشان Paulownia fortune و Paulownia tomentosa داد تيمار ميدان مغناطيسى در افزايش قابليت و كاهش دور دوره

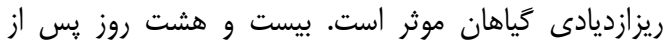

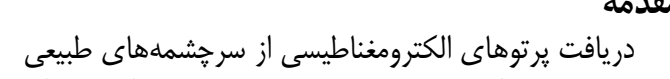

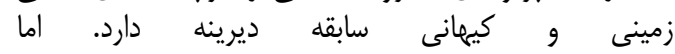

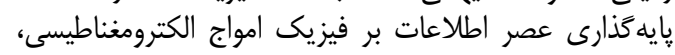

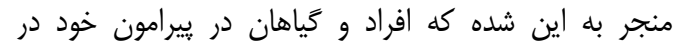

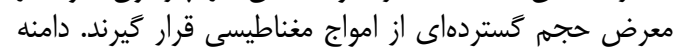

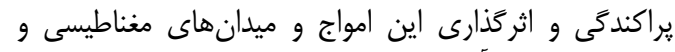

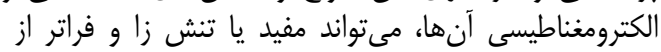

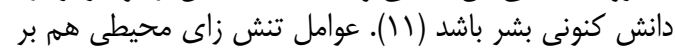

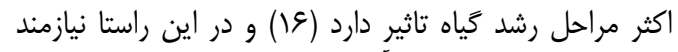

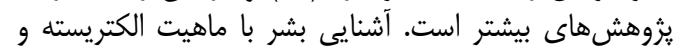

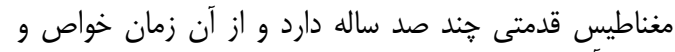

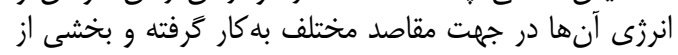

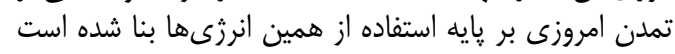

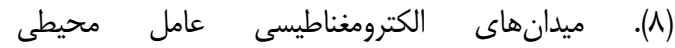
اجتنابنايذيرى براى جانداران هستند كه اخيرا تحقيقات زيادى إنى

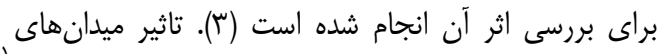

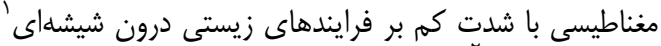

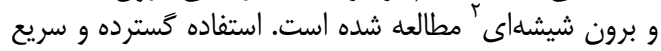

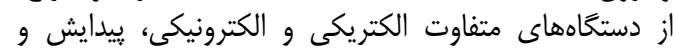
ظهور فر كانس هاى ميكروويو و راديويى، ميدانهاى مغناطيسى الكي 
دارند. در صورتى كه بتوان با استفاده از ميدان مغناطيسى در

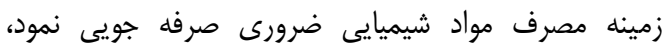

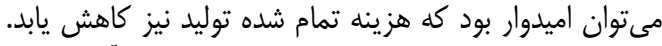

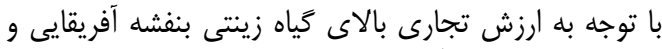

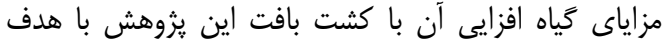

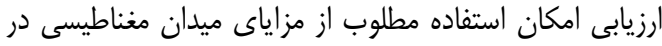

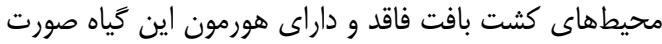
يذيرفت.

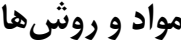 تمييه نمونها}

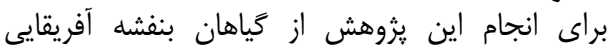
يكى از شركتهاى دانش بن بنيان (Saintpaulia ionantha)

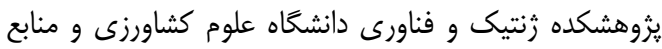

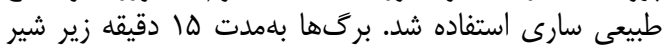

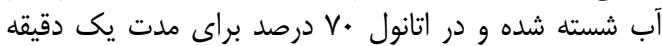

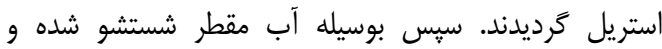

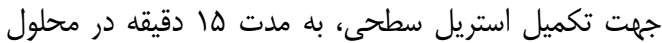

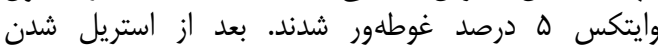

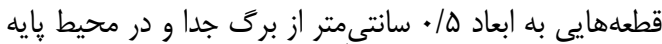

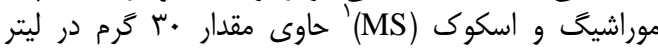

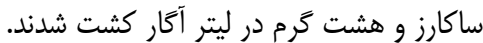

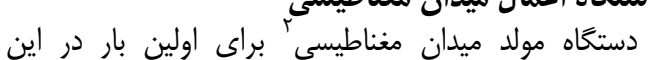

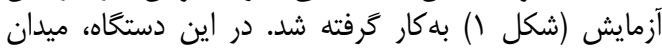
مغناطيسى حول لوله استوانهاى از جنس

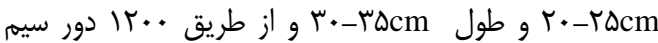
مسى به قطر يك ميلى ئى

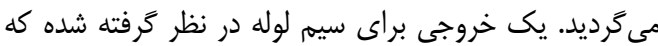

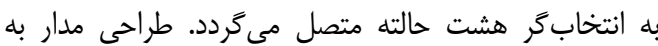

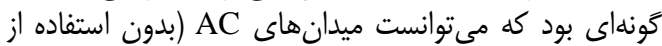
يل ديود) و DC (با استفاده از يل ديل ديود) ايجاد نمايد.
شروع كثت بافت، اثر مثبت ميدان مغناطيسى بر وزن ترك،

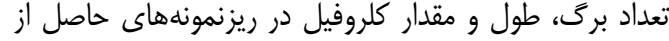

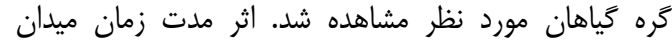

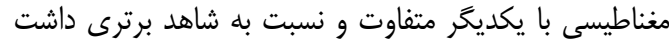

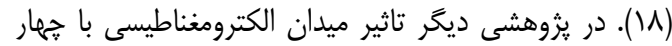

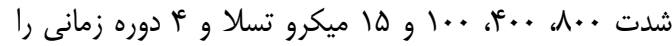

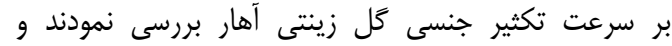

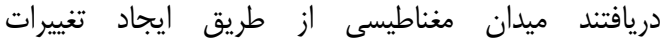

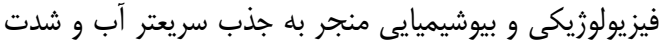

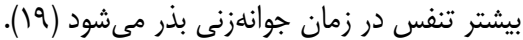

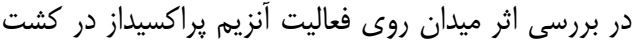

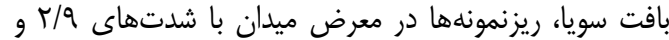

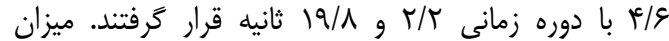

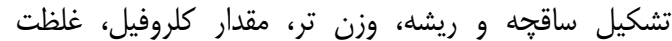
RNA

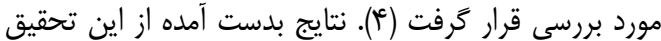

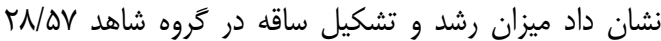

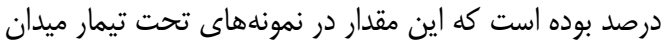

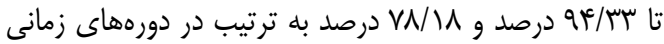

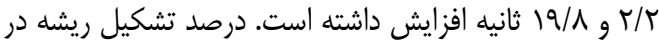
زروه شاهد

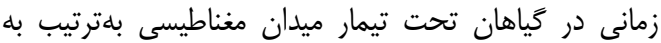
促V/IV

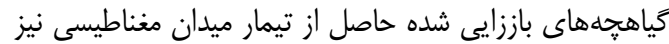
نسبت به شاهد افزايش داشت بارئ

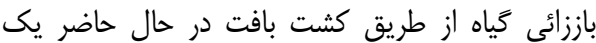

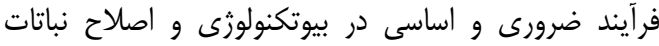

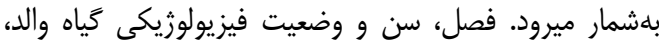

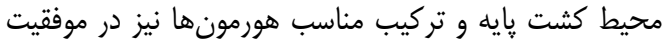

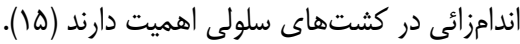

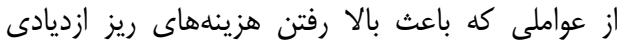

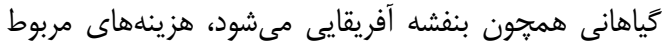

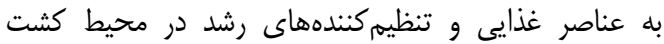

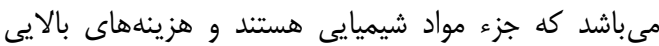

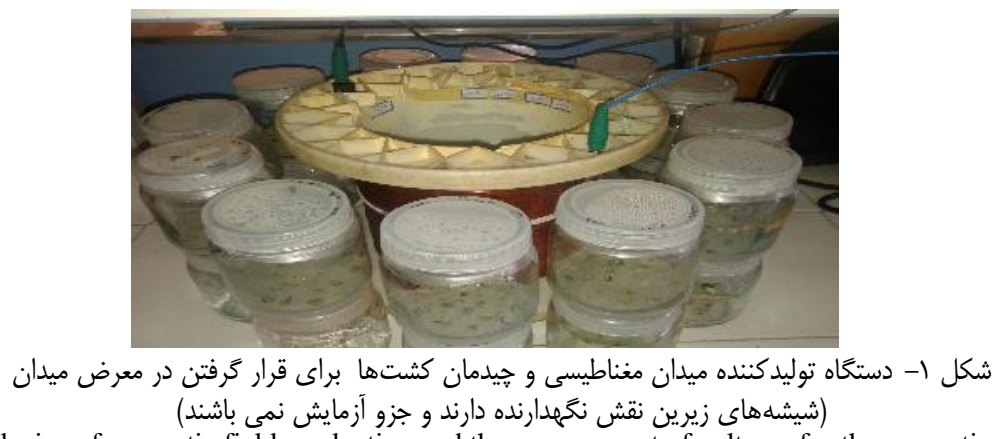

Figure1. The device of magnetic field production and the arrangement of cultures for the magnetic field exposure (only upper jams used and the under jams was base for upper ones) 
براى ايجاد هشت سطح متفاوت ولتاز و شدت مئ ميدان

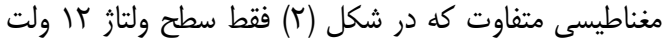

شكل (T) مدار و نحوه توليد ميدان مغناطيسى را نشان

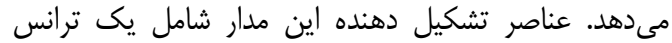

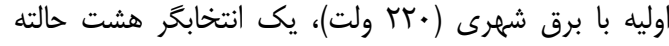

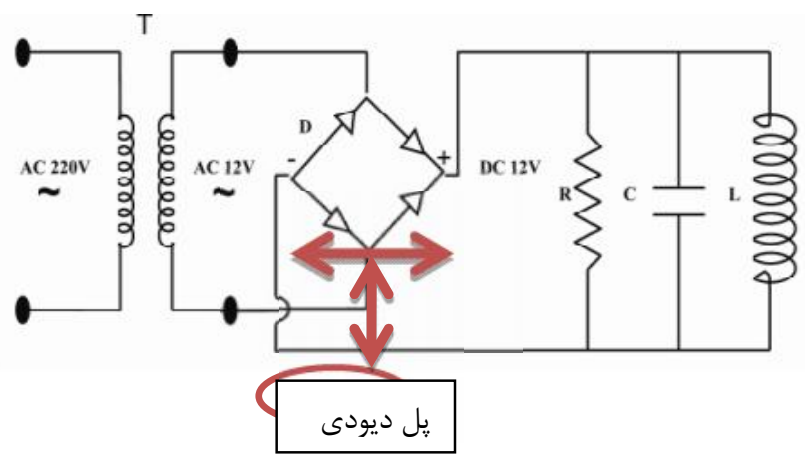

شكل r- مدار تشكيل ميدان مغناطيسى

Figure 2. Circuit formed magnetic field

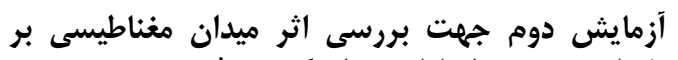

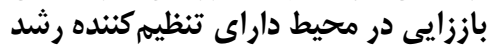

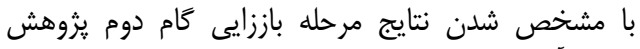

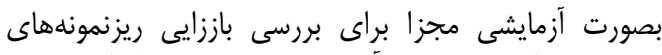

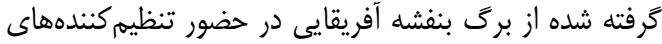

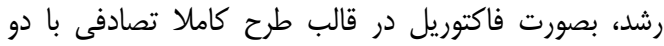

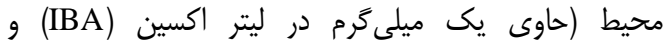

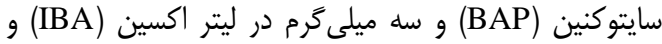

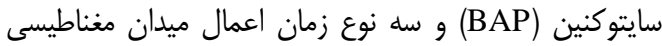

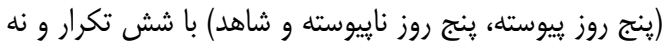

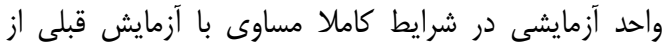

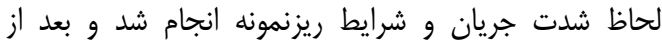

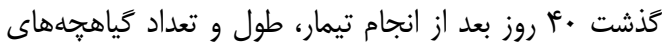

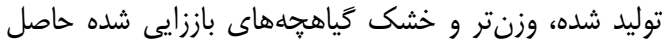

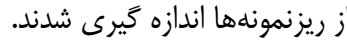

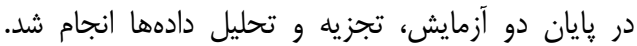

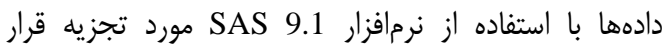
كرفت. همجنين مقايسه ميانخينها با روش راده دانكن در سطح

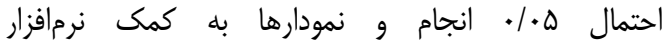
تجxcell 2010

نحوه اعمال ميدان مغناطيسى به تَّياهان

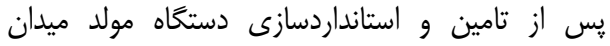

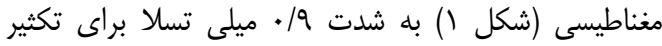

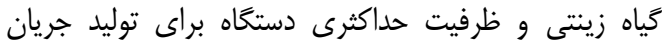

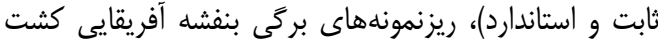

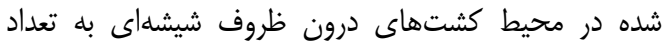

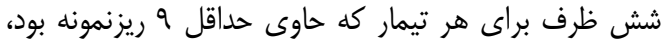

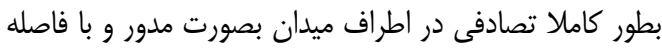

در اين يزوهش شدت ميدان مغناطيسى توسط دستخاه إنداه

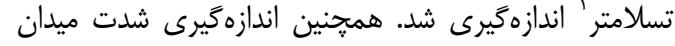

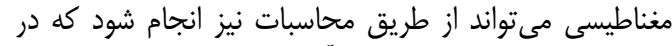

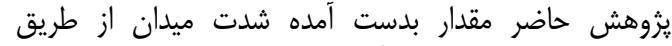

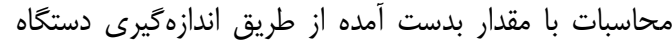

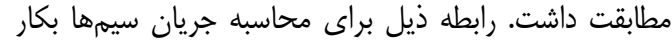

$\mathrm{B}=4 \pi \times 10^{-7} \frac{\mathrm{Nl}}{\mathrm{l}}$

مىرود. كه در اين رابطه B جـالى شار بر حسب تسلا، N N تعداد

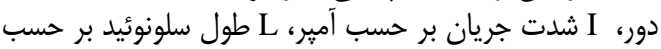

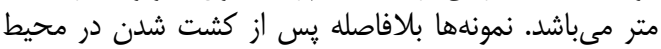

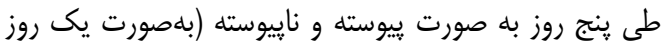

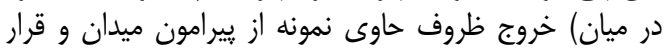

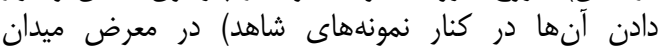

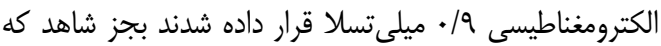

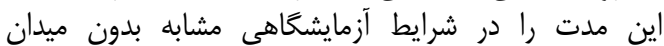
الكترومغناطيسى سيرى نمود.

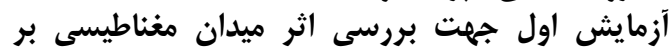
باززايى در محيط فاقد تنظيه كننده رو رشد

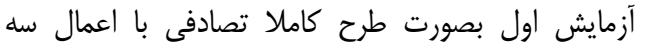

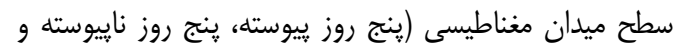

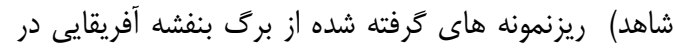

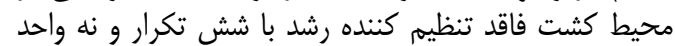

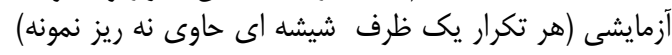

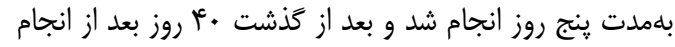

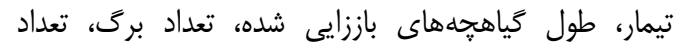

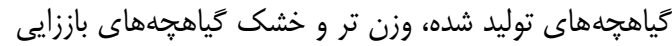

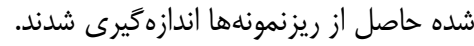


شد. براى اندازهخيرى وزنتر، نمونهها با استفاده از ترازوى

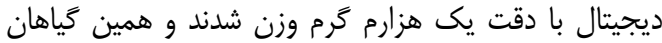

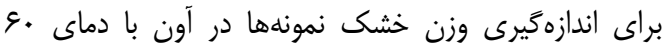

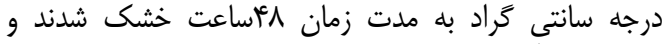

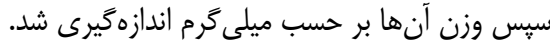

نتايج و بحث آزمايش اول: باززايى در محيط فاقد تنظيمكندههاى رشد

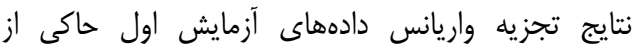

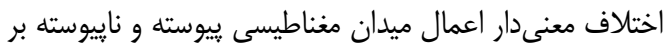

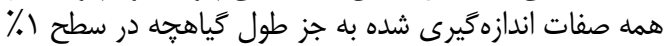

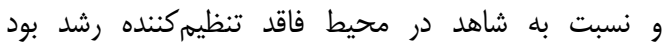

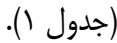

يكسان بر روى يكسرى ظروف بلهنوان پايه قرار داده شدند

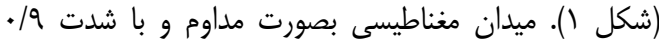

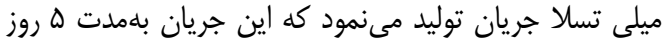

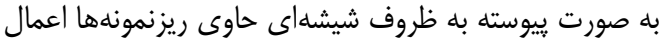

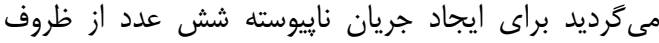

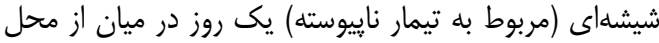

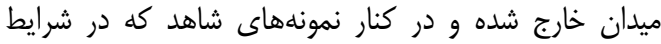

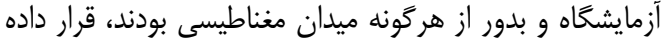

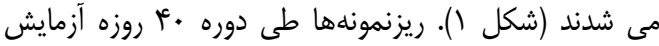

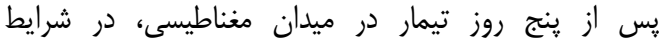

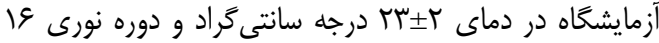

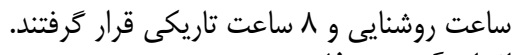
اندازهَيرى صفاعت روشنات

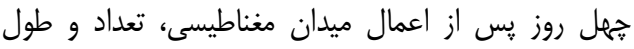

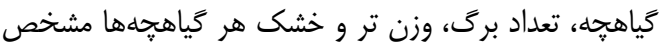

جدول ا- تجزيه واريانس اثر زمان هاى مختلف (ينج روز ييوسته و پنج روز ناييوسته) اعمال ميدان مغناطيسى (9/ • ميلى تسلا) بر خصوصيات

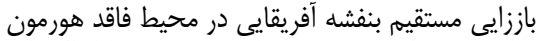

Table 1. Analysis of variance for the effect of different magnetic field (0/9 mT) times ( 5 continuous days and 5 noncontinuous days) on the features of direct regeneration in African violets in a hormone-free medium

\begin{tabular}{|c|c|c|c|c|c|c|}
\hline \multicolumn{6}{|c|}{ ميانخين مربعات } & \multirow[b]{2}{*}{ منابع تغييرات } \\
\hline وزنيلى خشرم) & (ميلى كرم) & (تعداد) & (سانتى متر) & 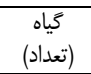 & درجه آزادى & \\
\hline$\% \cdots \gamma^{* * *}$ &.$/ 19^{* *}$ & $1 . / \Gamma \Psi^{*} * *$ & $1 / T \varepsilon^{\text {ns }}$ & D)/צ9** & $r$ & تيمار \\
\hline . $\ldots r$ &.$/ . r$ & $\cdot / \mu$ & • & $\cdot / N T$ & 10 & خطا \\
\hline$r r / q 1$ & $\mid r / \cdot r$ & $|r / \Lambda|$ & $1 F / M$ & | & - & ضرب تغييرات \\
\hline
\end{tabular}

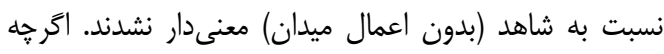

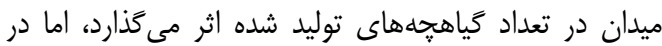

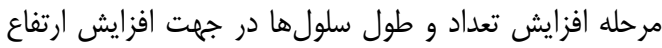

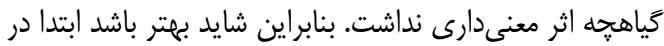

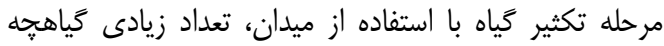

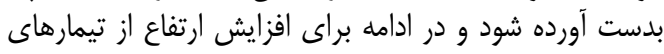
ديخر استفاده گردد.
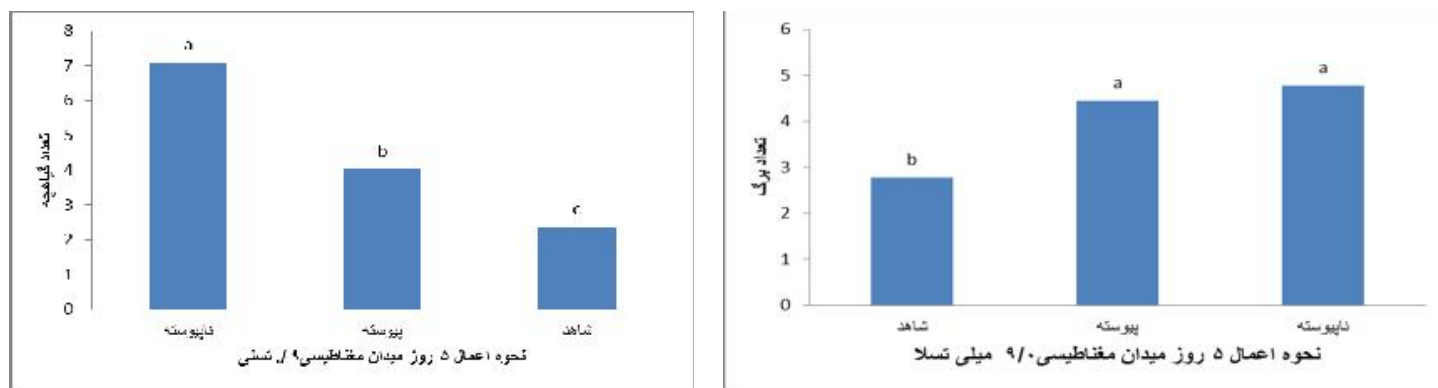

شكل זـ- اثر زمانهاى مختلف (ه روز متوالى و ه روز غير متوالى) اعمال ميدان مغناطيسى (9/ • ميلى تسلا) بر تعداد برى و كياهجه بنفشه آفريقايى در محيط فاقد هورال هورمون

Figure 3. The effect of different magnetic field ( $0.9 \mathrm{mT})$ times ( 5 continuous days and 5 noncontinuous days) magnetic field $(0.9 \mathrm{mT})$ on the number of leaf and plantlet of African violets in a hormone-free medium 


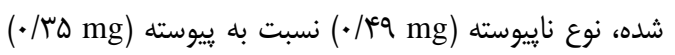

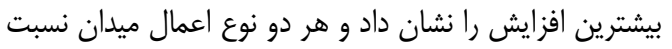

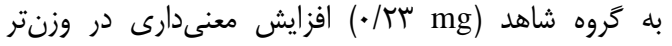
داشتند (شكل عاء).

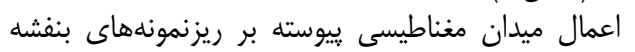

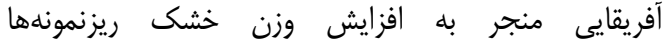

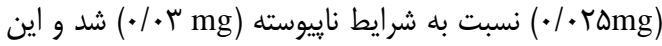

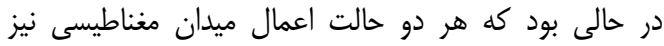

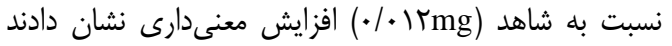

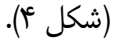

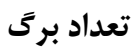

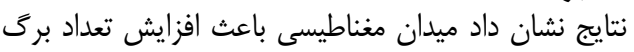

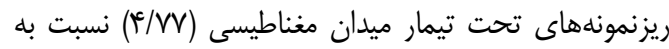

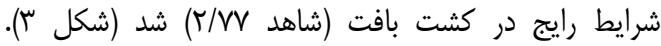

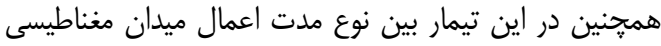

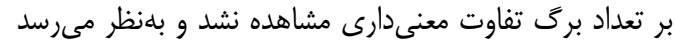

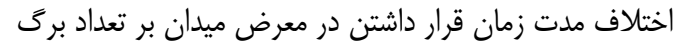

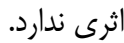

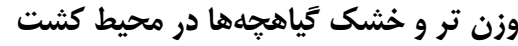

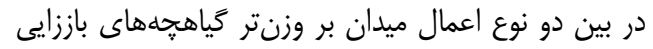

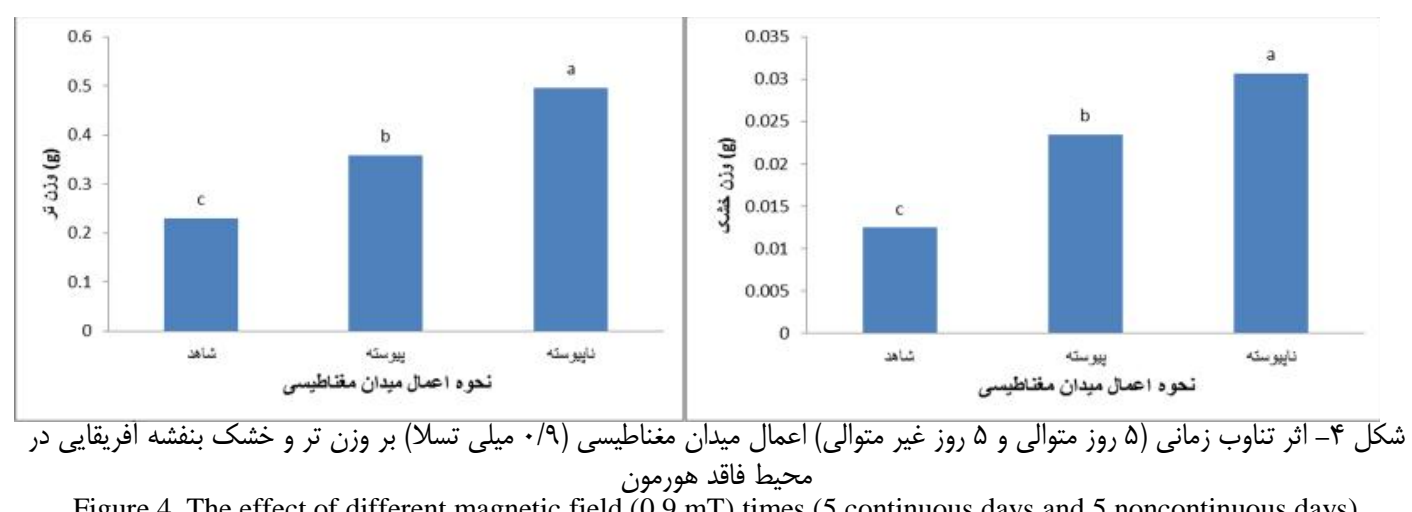

Figure 4. The effect of different magnetic field $(0.9 \mathrm{mT})$ times ( 5 continuous days and 5 noncontinuous days) magnetic field $(0.9 \mathrm{mT})$ on fresh and dry weight of African violets in a hormone-free medium

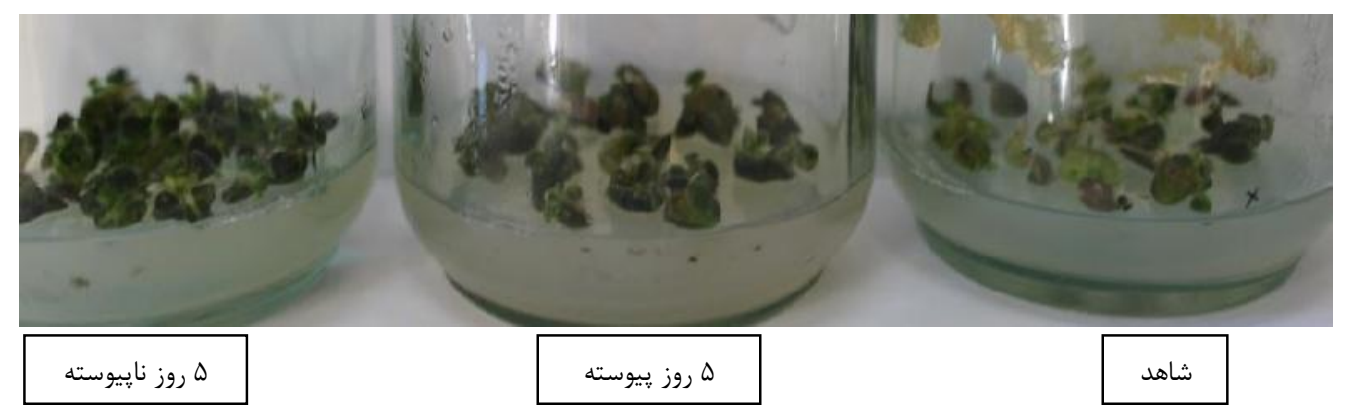

شكل ه- اثر ميدان مغناطيسى بر ريزنمونه هاى بنفشه آفريقايى در محيط فاقد هورمون

Figure 5. The effect of magnetic field on African violets explants in hormone-free medium

آفريقايى در محيط كشت حاوى هورمون IBA و و

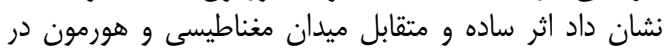

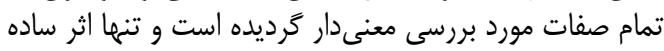

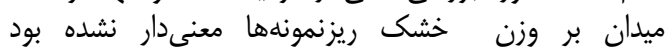

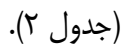

باززايى در محيط حاوى تنظيم كنندهایى رشد

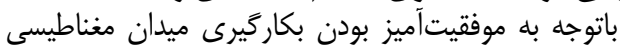

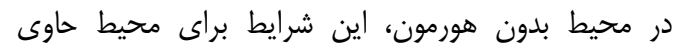

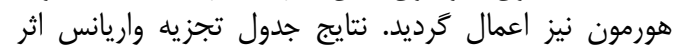

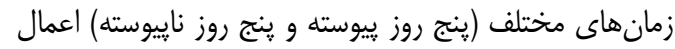

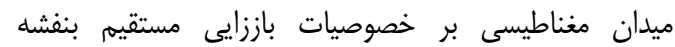




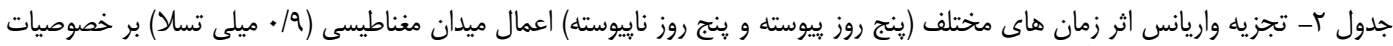

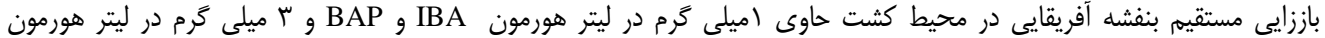

BAP, IBA

Table 2- Analysis of variance for the effect of different magnetic field $(0.9 \mathrm{mT})$ times $(5$ continuous days and 5 noncontinuous days) on the features of direct regeneration in African violets in a medium Containing hormone $\left(1 \mathrm{mgl}^{-1} \mathrm{IBA}+\mathrm{BAP}\right.$ and $\left.3 \mathrm{mgl}^{-1} \mathrm{IBA}+\mathrm{BAP}\right)$

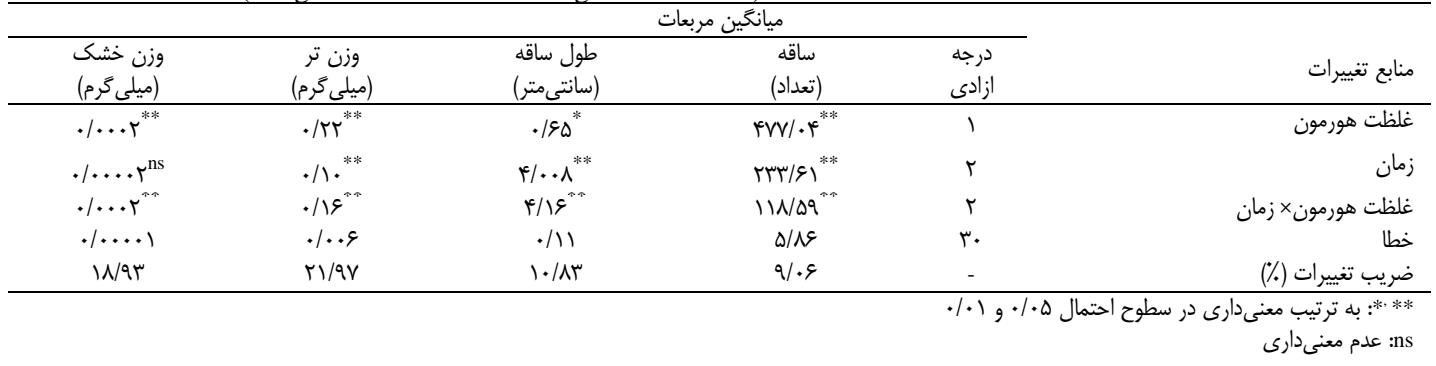

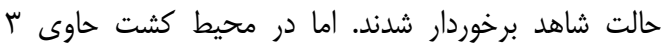

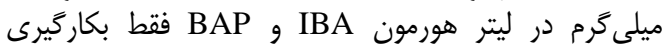

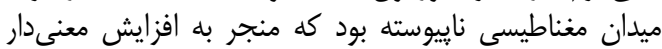

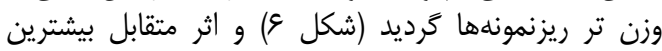

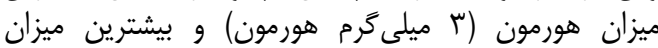

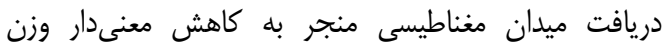
خشك ريزنمونهها نسبت به شاهد و شرايط ناييوسته كرديد.

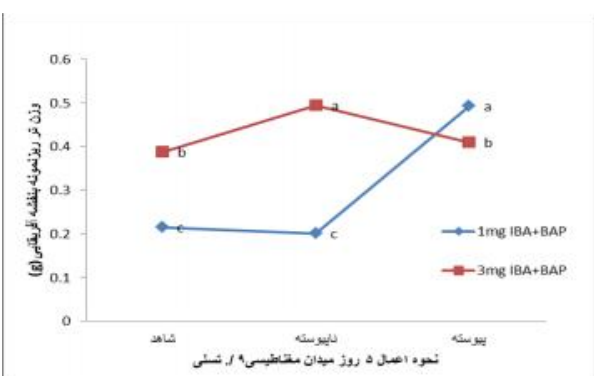

بنابر نتايج، وزنتر ريزنمونه،هاى باززايى شده شاهد درد

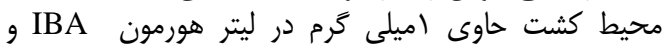

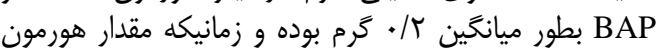

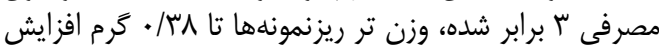

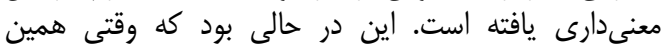

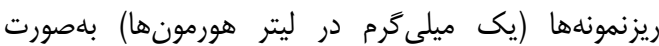

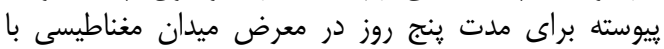

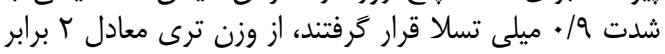

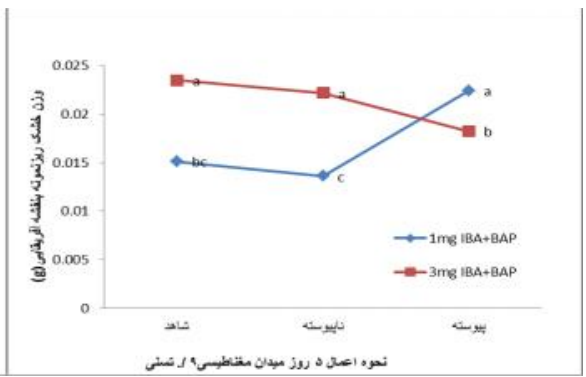

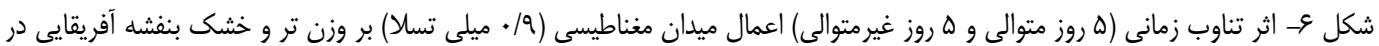

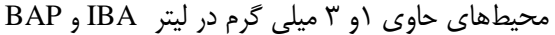

Figure 6. The interaction of effect of different magnetic field $(0.9 \mathrm{mT})$ times $(5$ continuous days and 5 noncontinuous days) magnetic field $(0.9 \mathrm{mT})$ on fresh and dry weight of African violets in a mediums included 1 and 3 $\mathrm{mgl}^{-1} \mathrm{IBA}$ and BAP

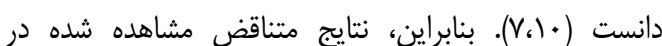

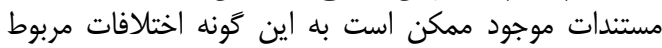
باشد.

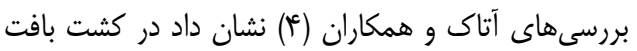

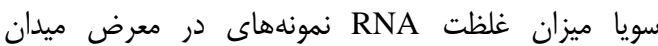

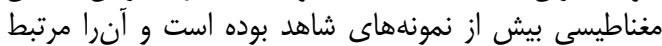

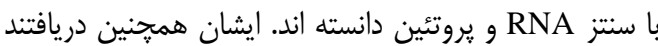

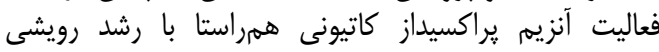

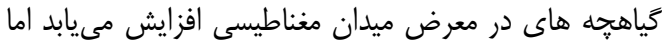

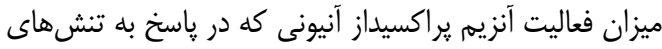

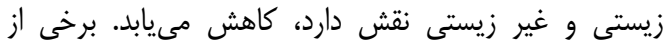

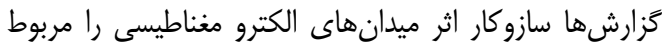

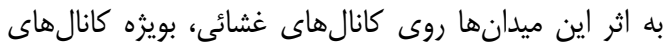
انتقال كلسيم ميدانند، بطوريكه با القاى ميدان الكتريكى و وانئ

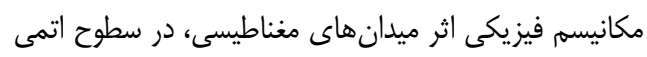

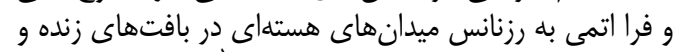
اثرات آن بر وضعيت اسبين الكترونيكى ' و ارتباط آنهائ آنها بان

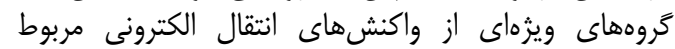

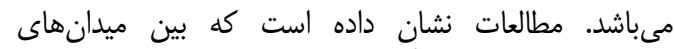

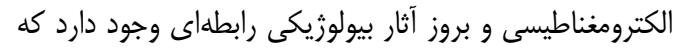

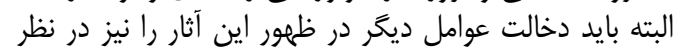

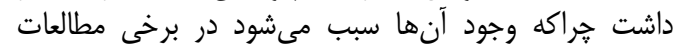

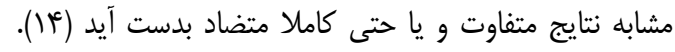

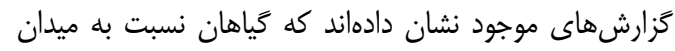

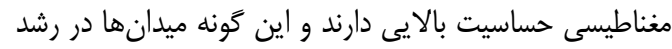

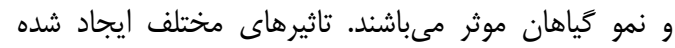

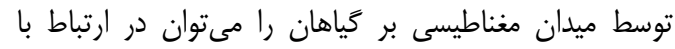

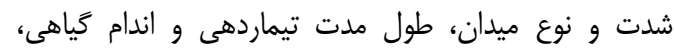


است (19) و در نتيجه موجب افزايش كارآيى گياه و افزايش

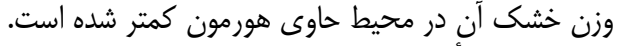

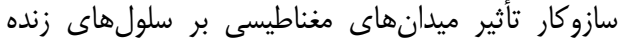

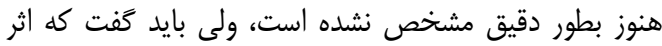

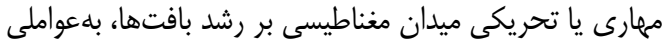

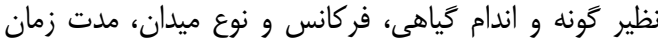

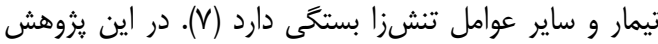

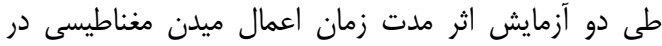

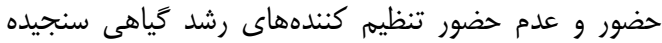

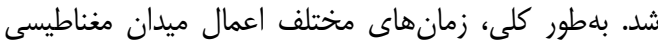

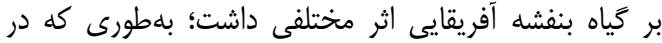

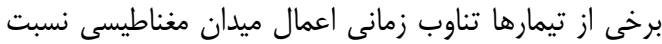

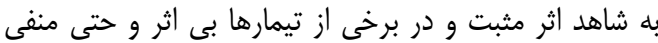

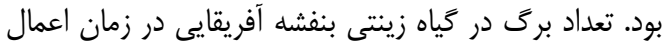

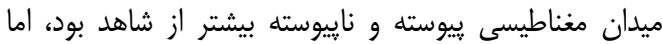

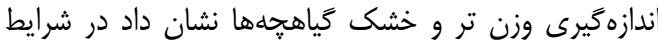

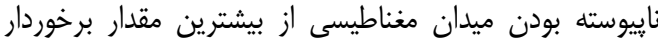

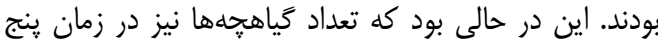

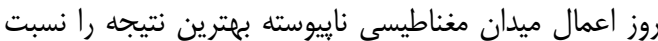

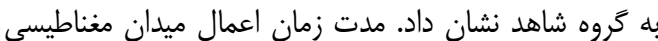

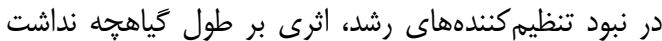

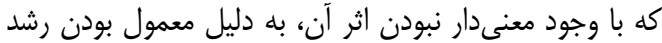

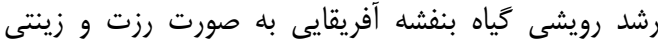

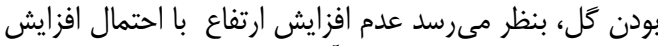

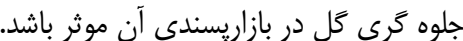

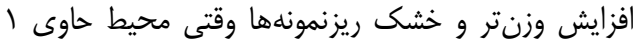
ميلى گرم در ليتر هورمون IBA و و

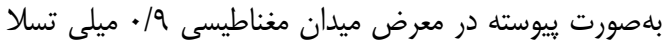

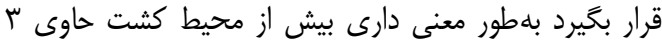
ميلى گرم در ليتر هورمون IBA و

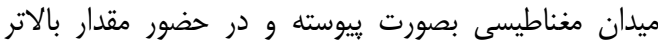

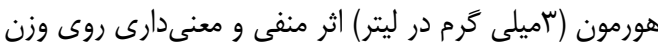

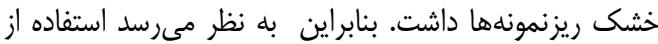

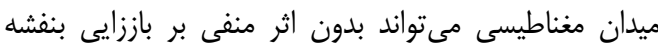

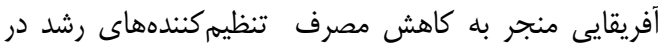

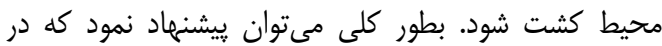

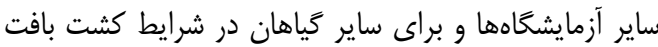

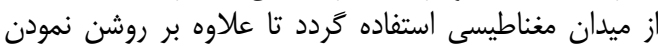

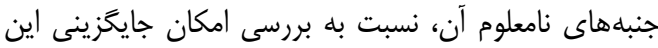

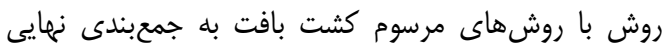

رسيد.

\section{تشكر و قدردانى}

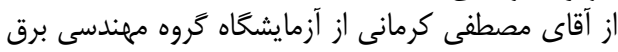

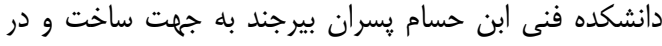

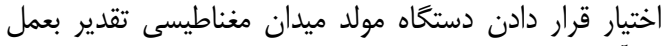

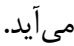

مغناطيسى به اين كانالها كه داراى بار الكتريكى هستند اين

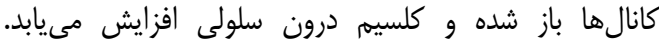

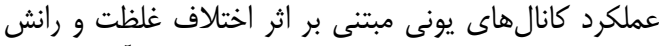

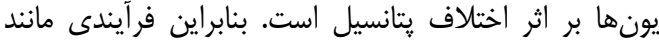

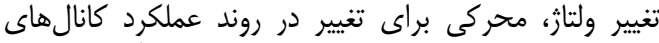

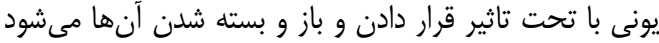

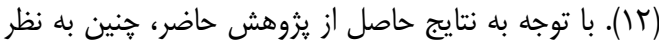

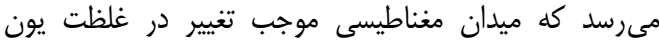

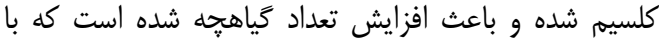

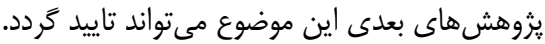

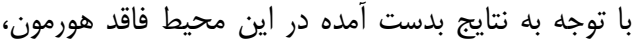

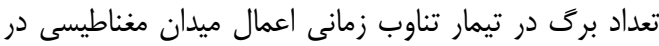

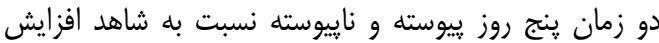

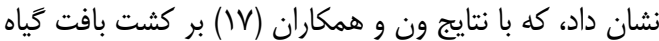

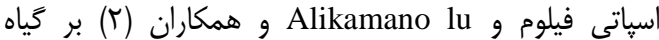
تابير Paulowinia tomentosa

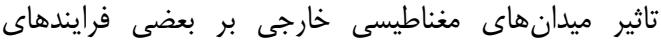

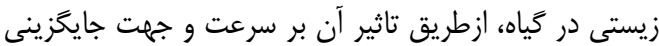

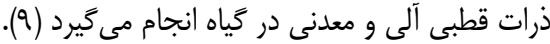

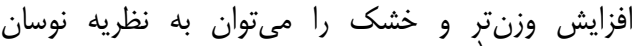

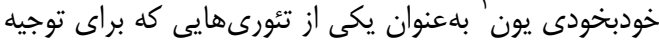

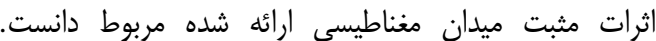

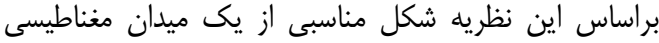

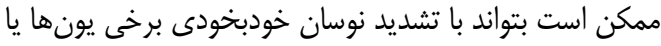

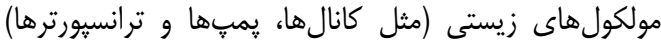

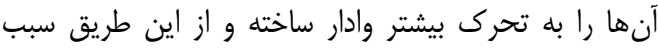

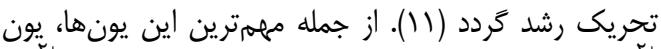

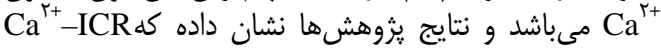

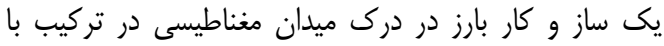
ميدان الكترومغناطيسى مى بـاشد (سار دار)

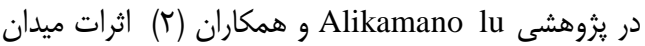
Paulowinia tomentosa مغناطيسى را بر كشت بر بافت بررسى كردند كه نسبت به شاهد افزايش دئ در برافياه برخى خصوصيات

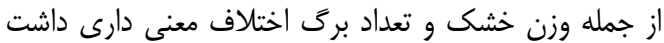
كه با نتايج يزوهش حزن حاضر مطابقت دارد.

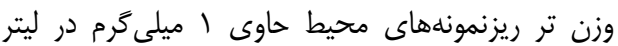

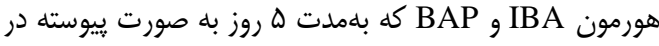

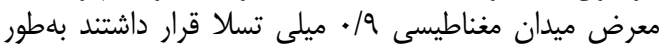

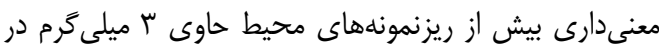

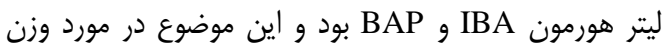

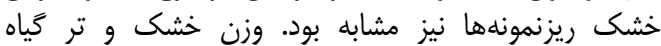

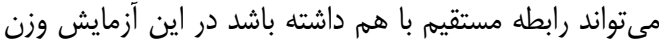

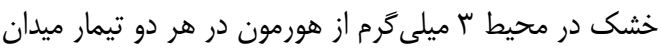

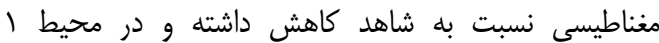

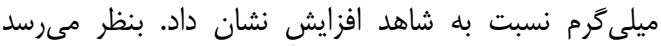

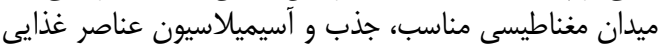

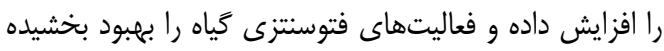

1- Ion cyclotron resonance 
11 . اثر ميدان مغناطيسى بر اندامزايى مستقيه ريزنمونه بنفشه آفريقايى

1. Abaszadeh, R. M. Masumiyan, S.H. Sarami, A. Zenuzi, A. Nouruziyan and F Sadatmirsafi 2014 Study the effects of electromagnetic fields on phenol the amount Production of Aloe vera. In proceedings of The 3th conference of Electromagnetic engineered (COM) Iran, 3-4 Des., Ministry of Science, Research and Technology scientific and industrial research organization in Iran, pp: 1-6 (In Persian).

2. Alikamanoğlu, S., O. Yaycılı, C. Atak and A. Rzakoulieva. 2007. Effect of magnetic field and gama radiation on Paulowinia tomentosa tissue culture. Biotechnology \& Biotechnological Equipment, 21, 49-53, Retrieved 30 January 2016, from http://dx.doi.org/10.1080/13102818.2007.10817412.

3. Arbabian, S., A. Majd and S. Salaripour .2010. The effects of electromagnetic field (EMF) on vegetative organs, pollen development, pollen germination and pollen tube growth of Glycine max L. Cell and Tissue Journal, 1: 35-42 (In Persian).

4. Atak, C., O. Çelik, S. Alikamanoğlu and A. Rzakoulieva. 2007. Effect of magnetic field on peroxidase activities of soybean tissue culture. Biotechnology \& Biotechnological Equipment, 21(2): 166-171.

5. Atharinia, M., M. Nori and F. Ghanati. 2009. Effect of static magnetic field on certain physiological and biochemical features of Cicer arietinum in vegetative growth phase. Pajouhesh \& Sazandegi, 80: 62-74 (In Persian).

6. Çelik, Ö., Ç. Atak and A. Rzakulieva. 2008. Stimulation of rapid regeneration-by a magnetic field in Paulownia node cultures. Journal of Central European Agriculture, 9: 297-30412.

7. Kato, R., H. Kamada and M. Asashma.1989. Effect of high and very low magnetic field on the growth of hairy roots of Daucus carotta and Atropa belladonna. Cell Physiology, 30: 605-608.

8. Khoshsokhan-Mozafar, M., F. Ghanati, H. Zare Maivan, P. Abdolmaleki, K.H. Khorrami Shad and M. Vaeszadeh.2006. The effects of static magnetic field on the metabolism of certain phenolic compound in red cabbag (Brassica oleracea L. cv. Staccato). Pajouhesh \& Sazandegi, 70: 63-69 (In Persian).

9. Kordas, L. 2002. The effect of magnetic field on growth, development and the yield of spring wheat. Polish Journal of Environmental Studies, 11: 527-530.

10. Liboff, A.R., B.R. McLeod and S.D. Smith.1989. Rotating magnetic fields and iron cyclotron resonance Journal of Bioelectronics, 8: 119-125.

11. Paeez, A., F. Ghanati, M. Behmanesh, P. Abdolmaleki and B. Nahidian. 2012. Comparative study on the effect of static and electromagnetic fields on the some physiological properties at vegetative stage of wheat. In: Proceedings of 1th national conference on plant stress (abiotic), Isfahan University, Isfahan, Iran, pp: 1-3.

12. Paul, A., F. Robert and M. Meisel. 2006. High magnetic field induced changes of gene expression in Arabidopsis. Biomagnetic Research and Technology, 14: 103-7.

13. Pazur, A. and V. Rassadina. 2008. Transient effect of weak electromagnetic fields on calcium ion concentration in Arabidopsis thaliana. BMC Plant Biology, Received: 26 November 2008, from http://www.biomedcentral.com/1471-2229/9/47.

14. Rajabbeigi, E., F. Ghanati, F. Sefidkon and P. Abdolmaleki. 2007. Investigating the changes of essential oil of Ocimum basilicum L. in response to electromagnetic field. Iranian Journal of medicinal and Aromatic Plants, 22(4): 341-350.

15. Sadeghian, S., Gh. Ranjbar and K. Kazemitabar. 2014. Consideration and selection of suitable Hormonal Composition for in vitro Shoot Regeneration and propagation of Ocimum basilicum L. Journal of 1Crop Breeding, 6(13): 40-48 (In Persian).

16. Tahmasbe, A., M.A. Asghari, O. Sofalian, H.R. Mohammaddoust, C. Abad and A. Rasoulzadeh. 2016. Effect of osmotic stress on some physiological characters of wheat cultivars. Journal of Crop Breeding, 8(19): 112-123 (In Persian).

17. Van, P.H., J. Silva, L. Ham and M. Tanaka. 2012. Effects of permanent magnetic fields on in vitro growth of Cymbidium and Spathiphyllum shoots. In Vitro Cellular \& Developmental Biology Plant, 48: 225-232.

18. Yaycili, O. and S. Alikamanoglu. 2005. The effect of magnetic field on Paulownia tissue cultures. Plant Cell Tissue Organ Culture, 83: 109-114.

19. Zamiran, A., M.R. Maleki and V.R. Safari. 2011. Effect of magnetic field on seed germination rate of Zinnia. In: Proceedings of 1 th national congress of modern science and technology of agriculture, Zanjan University, Zanjan, Iran, pp: 1-4. 


\title{
The Effect of Different Magnetic Field Duration on Direct Organogenesis of African Violets (Saintpaulia Ionantha) In Tissue Culture Medium with and Without Pgrs
}

\author{
Masumeh Rahmatinia ${ }^{1}$, Hosein Moradi $^{2}$, Vali Allah Ghasemi Omran ${ }^{3}$ and \\ Mehdi Hadadinejad

\footnotetext{
1- Graduated M.Sc. Student of Department of Horticultural Sciences, Sari Agricultural Sciences and Natural Resources University

2 and 4- Assistant Professors of Department of Horticultural Sciences, Sari Agricultural Sciences and Natural Resources University (Corresponding Author: moradiho@yahoo.com)

3- Assistant professor of Genetic and Biotechnology Institute from Sari Agricultural Sciences and Natural Resources

Received: October 16, 2016 University

Accepted: February 26, 2017
}

\begin{abstract}
To study intermittence of duration of exposure to magnetic field or MF $(0.9 \mathrm{mT})$ on direct organogenesis of African violet explant in medium with and without PGRs these experiments performed. First experiment performed as completely randomized design (CRD) with three level of MF exposure (control, 5 day continuous and 5 day discontinuous) in PGR- free medium included via 6 repeat. The second experiment performed as factorial in CRD. Factors included auxin and cytokenin as two PGRs in $1 \mathrm{mg}$ Lit and 3mg Lit IBA and BAP levels and 3 levels of MF exposure as well as first experiment with 6 repeat. The results showed that explants exposed to a discontinuous MF with and without PGRs produced the highest shoot number (7.08) and the lowest number was produced in the control (2.35). Plantlets length was not affected by the MF but it was affected inside of PGRs. The leaf number in the continuous (4.4) and discontinuous (4.7) magnetic field was approximately doubled in comparison with control (2.77). The fresh and dry weight revealed better values in the MF discontinuous (0.49 and 0.03 $\mathrm{mg}$ ) than continuous ( 0.35 and $0.02 \mathrm{mg}$ ) in PGRs-free medium. Results showed the fresh weight of plantlets was significantly higher for $1 \mathrm{mgl}-1$ PGRs than $3 \mathrm{mgl}-1$ PGRs, when exposed to 0.9 mT MF for 5 days continuously, as well as for dry weight. It seems that the MF as a light abiotic stress can simulate the cell division and elongation and eventually the plant growth.
\end{abstract}

Keywords: Explant, Fresh and dry weight, Stress, Saintpaulia ionantha 